\title{
Scutellarin is Highly Likely to be Responsible for Drug-Drug Interactions Mediated by Hepatic Organic Anion-Transporting Polypeptide IB3
}

\author{
Jianming Liu' ${ }^{\prime}$ Yongmei Guo ${ }^{2} \cdot$ Yanqi Xu ${ }^{2} \cdot$ Li Yuan $^{3} \cdot$ Huiting Zhu ${ }^{4,5}$
}

Received: 28 July 2020 / Accepted: 7 October 2020 / Published online: 29 October 2020

(C) The Author(s) 2020

\begin{abstract}
Purpose Scutellarin, a flavonoid derived from the plant Erigeron breviscapus, is currently widely used to treat cerebrovascular diseases, liver-related diseases, and hyperlipidemia in china and other East Asian countries. This study was to investigate the effect of scutellarin on the uptake of rosuvastatin in HEK293T cells expressing human organic anion transporting polypeptide 1B3 (hOATP1B3) and rat OATP1B2 (rOATP1B2), respectively, and the effect of scutellarin on the pharmacokinetics of rosuvastatin in rats.

Methods The newly established HEK293T cells expressing hOATP1B3 and rOATP1B2 were used to examine the effects of scutellarin and positive controls on in vitro rosuvastatin transport. After co-feeding with scutellarin, the rosuvastatin area under the plasma concentration-time curve $\left(\mathrm{AUC}_{0-24 \mathrm{~h}}\right)$, the peak plasma drug concentration $\left(C_{\max }\right)$, elimination halflife $\left(t_{1 / 2}\right)$, time to reach $C_{\max }\left(t_{\max }\right)$, clearance $(\mathrm{CL})$ and apparent clearance $(\mathrm{CL} / \mathrm{F})$ of rosuvastatin were determined in rats.
\end{abstract}

Jianming Liu and Yongmei Guo contributed equally to this work.

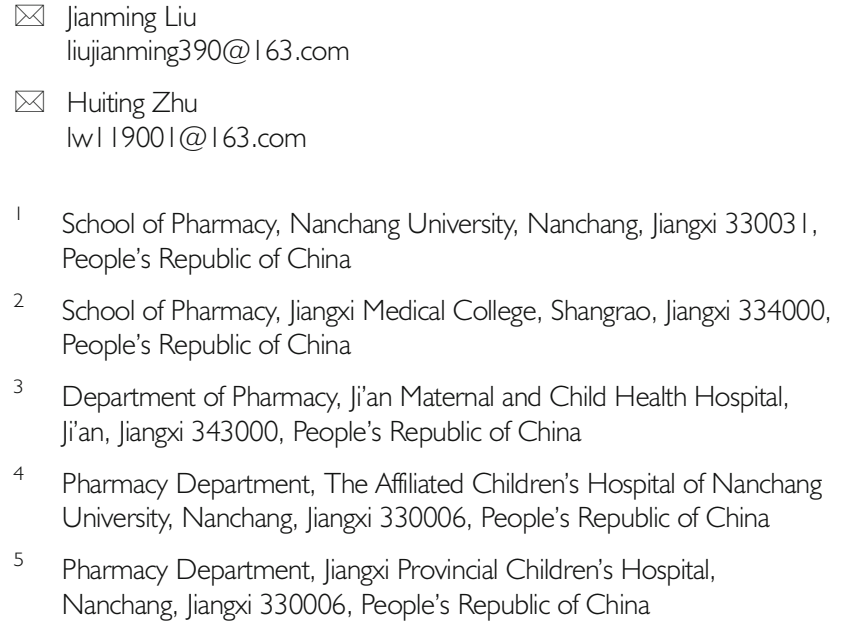

2 School of Pharmacy, Jiangxi Medical College, Shangrao, Jiangxi 334000, People's Republic of China

3 Department of Pharmacy, Ji'an Maternal and Child Health Hospital, Ji'an, Jiangxi 343000, People's Republic of China

4 Pharmacy Department, The Affiliated Children's Hospital of Nanchang University, Nanchang, Jiangxi 330006, People's Republic of China

5 Pharmacy Department, Jiangxi Provincial Children's Hospital, Nanchang, Jiangxi 330006, People's Republic of China

Results Scutellarin inhibited hOATP1B3- and rOATP1B2mediated rosuvastatin uptake (IC50: $45.54 \pm 6.67 \mu \mathrm{M}$ and $27.58 \pm 3.97 \mu \mathrm{M}$ ) in vitro in a concentration-dependent manner. After co-feeding with scutellarin, the $\mathrm{AUC}_{0-24 \mathrm{~h}}$ and $C_{\max }$ of rosuvastatin in rats increased to $27.4 \%$ and $37.7 \%$, respectively. The $t_{1 / 2}$ and $t_{\max }$ of rosuvastatin showed no significant change. Moreover, scutellarin caused $29.2 \%$ and $28.1 \%$ decrease in the $\mathrm{CL}$ and $\mathrm{CL} / \mathrm{F}$ of rosuvastatin.

Conclusion Scutellarin may inhibit the hOATP1B3- and rOATP1B2-mediated transport of rosuvastatin in vitro, and exerts a moderate inhibitory effect on the pharmacokinetics of rosuvastatin in rats. Scutellarin is highly likely to participate in drug-drug interactions, as mediated by OATP1B3 in humans.

KEY WORDS drug-drug interactions (DDI) · organic anion transporting polypeptide IB3 (OATP I B3) · rosuvastatin . scutellarin

$\begin{array}{ll}\text { ABBREVIATIONS } \\ \text { AUC } & \text { Area under the plasma concentration-time curve } \\ C_{\max } & \text { Peak plasma drug concentration } \\ \text { CL } & \text { Clearance } \\ \text { CL/F } & \text { Apparent clearance } \\ \text { DDI } & \text { Drug-drug interactions } \\ \text { GA } & \text { Glycyrrhizic acid } \\ \text { LC/MS/ } & \text { Liquid chromatography-tandem mass } \\ \text { MS } & \text { spectrometry } \\ \text { OATP } & \text { Organic anion transporting polypeptide } \\ \text { RSV } & \text { Rosuvastatin } \\ \text { RIF } & \text { Rifampicin } \\ \text { SCU } & \text { Scutellarin } \\ t_{\max } & \text { Time to reach } C_{\text {max }} \\ t_{I / 2} & \text { Elimination half-life } \\ \text { CMC-Na } & \text { Carboxymethylcellulose sodium }\end{array}$




\section{INTRODUCTION}

Traditional Chinese Medicine still plays an important role in protecting public health in countries like China and Japan (1). Scutellarin (SCU), a flavonoid derived from the plant Erigeron breviscapus, is an active ingredient of a variety of Chinese herbal medicine, with broad pharmacological effects and clinical applications (2). SCU is currently widely used to treat cerebrovascular diseases, liver-related diseases, and hyperlipidemia $(3,4)$. It is estimated that over ten million Chinese patients are taking SCU and its related drugs annually (5). Meanwhile, drug-drug interactions (DDI) adverse events have attracted increasing attention (6). At the pharmacokinetic level, various interactions between traditional Chinese medicine and drugs may occur, especially in the liver (7). The metabolism and disposition of drugs in the liver plays a critical role in both drug detoxification and drug toxification (8). Transporters play a vital role in drug pharmacokinetics, and competing for them is crucial for drug uptake, distribution, and elimination $(9,10)$. The organic anion-transporting polypeptides (OATPs) may mediate DDI when drugs pass through the hepatic sinusoids (11). Both genetic variation and DDI may change the transport function of human OATP1B 1 (hOATP1B 1) and human OATP1B3(hOATP1B3) thus frequently trigger severe adverse events, for example, statin-induced rhabdomyolysis (12). In previous studies, we have shown that SCU affects the uptake of rosuvastatin (RSV) in rat primary hepatocytes and HEK293T-hOATP1B1 cells (13). Besides, hOATP1B1 and hOATP1B3 proteins share $80 \%$ identity in amino acid sequences in humans (14) and have common substrates like rifampicin (RIF) (15) and RSV (16). Rat OATP1B2(rOATP1B2) also locates in the sinusoidal plasma membrane and RSV is also its substrate (17). In rodents, OATP1B2 is considered as the closest ortholog to hOATP1B1 and hOATP1B3 (18). In vivo distribution of SCU is mainly in hepatocytes, the main target cells of HMG-GoA reductase statins (19). Up to now, a large number of studies have confirmed the pharmacokinetic interaction between SCU and statins $(2,20)$. Though SCU is known to affect the uptake of RSV in the cells expressing hOATP1B 1 (13), it remains unclear whether SCU affects RSV uptake in cells expressing hOATP1B3 or rOATP1B2, or is involved in pharmacokinetic DDI. Therefore, the in vitro or in vivo mechanisms underlying uptake of RSV remains to be clarified. Considering that most hOATP1B1 inhibitors will also inhibit hOATP1B3 clinically, SCU may be involved in DDI of these transporters.

In this study, we aimed to determine the potential effect of SCU on the activity of hOATP1B3 and rOATP1B2 transporters in vitro and to assess the effect of SCU on the pharmacokinetics of RSV in rats.

\section{MATERIALS AND METHODS}

\section{Materials}

SCU (purity $\geq 98 \%$, HPLC) was purchased from Kunming Double Star Technology Development Co.Ltd. RSV calcium (purity $\geq 98 \%$, HPLC) was purchased from Zhejiang Xindonggang Pharmaceutical Co.Ltd. Atorvastatin (internal standard) and RIF (purity $\geq 98 \%$, HPLC) were sourced from the National Institute for the Control of Pharmaceutical and Biological Products. Sodium butyrate (purity $\geq 98 \%$, HPLC) was provided by Sigma-Aldrich. Glycyrrhizin acid (GA) (purity $\geq 98 \%$, HPLC) was purchased from Shanghai Yuanye Biotechnology Co.Ltd. Polyclonal antibodies against hOATP1B3, rOATP1B2 and $\mathrm{Na}+/ \mathrm{K}+$-ATPase were sourced from Proteintech Co. Ltd. The transporter gene plasmid was provided by Shanghai Jikai Gene Co. Ltd. Human embryonic kidney $293 \mathrm{~T}$ (HEK293T) cell line was sourced from the Institute of Basic Medical Sciences, Chinese Academy of Medical Sciences (Beijing, P. R. China).

\section{Cell Culture and Transfection}

HEK293T cells were cultured at $37^{\circ} \mathrm{C}$ in Minimum Essential Medium supplemented with 10\% FBS (Sigma-Aldrich), $100 \mathrm{U} \cdot \mathrm{mL}^{-1}$ penicillin, and $100 \mathrm{mg} \cdot \mathrm{mL}^{-1}$ streptomycin in a humidified $5 \% \mathrm{CO}_{2}$ atmosphere. HOATP1B 3 and rOATP1B2 cDNA were respectively transfected into HEK293T cells according to the manufacturer's instructions. Cells were selected by adding G418 $\left(1 \mathrm{mg} \cdot \mathrm{mL}^{-1}\right)$ to the culture medium to obtain HEK293T-hOATP1B3 and HEK293T-rOATP1B2 cells. Cell transfection is successful and it can be used for a transport experiment after about 3 passages. Then, the HEK293T cells selected by $6 \mathrm{mg} \cdot \mathrm{mL}^{-1}$ blasticidin and colonies were picked up. The HEK293T cells with the highest transport activities were used for functional analysis. To induce the expression of hOATP1B 3 and rOATP1B2, sodium butyrate $(2.5 \mathrm{mM})$ was added to the medium $24 \mathrm{~h}$ before use.

\section{Western Blot Analysis}

According to a previous study (13), the cell suspension was prepared by digesting HEK293T, HEK293T-MOGK, HEK293T-hOATP1B3, and HEK293T-rOATP1B2 cells at the logarithmic proliferative phase with trypsin. Cells were lysed with SDS protein lysate, and cell proteins were extracted by centrifugation. The total protein concentration was determined using the 2-quinolinic acid (BCA) method. Then, 10\% 
sodium dodecylbenzene sulfonate polyacrylamide was used to transfer the proteins to polyvinylidene fluoride membrane (PVDF) by gel electrophoresis. The samples were blocked in $5 \%$ milk at room temperature for $1 \mathrm{~h}$, then the primary antibody was added and incubated overnight at $4^{\circ} \mathrm{C}$. The membrane was briefly rinsed for $5 \mathrm{~min}$ in TBST, which was repeated 3 times. The secondary antibody and goat anti-rabbit antibody conjugated to horseradish peroxidase were added and incubated at room temperature for $1 \mathrm{~h}$, and then the membrane was rinsed 3 times with TBST, 10 min each time. The ODYSSEY imaging system was applied to add ECL chemiluminescence developer for image acquisition.

\section{Transport Assay}

HEK293T-MOGK, HEK293T-hOATP1B 3, and HEK293T-rOATP1B2 cells were seeded in a 24-well plate coated with poly-L-lysine at an initial density of $2 \times 10^{5}$ cells/ well. $24 \mathrm{~h}$ after the cell seeding plate, sodium butyrate was added to induce transporter protein expression for $24 \mathrm{~h}$. Then, the cells were washed twice and pre-incubated with Krebs-Henseleit buffer at $37^{\circ} \mathrm{C}$ for $10 \mathrm{~min}$, and then incubated in $200 \mu \mathrm{L}$ of Krebs-Henseleit buffer cells containing RSV $(50 \mu \mathrm{M})$ and $\mathrm{SCU}(50 \mu \mathrm{M})$ or the vehicle $(0.2 \%$ dimethyl sulfoxide) at $37^{\circ} \mathrm{C}$ for $10 \mathrm{~min}(13)$. RIF $(50 \mu \mathrm{M})$ was used as an inhibitor (positive control) against OATP1B3.GA $(20 \mu \mathrm{M})$ was applied as an inhibitor against OATP1B2 (positive control) (21). RSV $(50 \mu \mathrm{M})$ was incubated with HEK293ThOATP1B3 and HEK293T-rOATP1B2 cells in the presence of SCU with increasing concentrations $(0.01-200 \mu \mathrm{M})$ for $10 \mathrm{~min}$. After removing the incubation buffer, the uptake reaction was terminated by adding ice-cold Krebs-Henseleit buffer, then discarded all the solutions and lysed with water by repeated freezing and thawing. Aliquots $(200 \mu \mathrm{L})$ were vortexed and centrifuged for $5 \mathrm{~min}$ at $18000 \mathrm{~g}$. The concentration of RSV was determined by the liquid chromatography with tandem mass spectrometric detection (LC/MS/MS) and the remaining $50 \mu \mathrm{L}$ aliquots of the cell lysis solution were used to determine the protein concentration with BSA as a standard. The RSV uptake is expressed as a percentage of the control.

\section{LC/MS/MS Assay for RSV}

The RSV concentrations accumulated in cells were determined using a validated LC/MS/MS method (13). The samples were prepared by adding $100 \mu \mathrm{L}$ of internal standard solution $\left(200 \mathrm{ng} \cdot \mathrm{mL}^{-1}\right.$, atorvastatin diluted in dimethyl sulfoxide) to $100 \mu \mathrm{L}$ of cell lysates. Mass spectrometric detection was performed with the assistance of an API 4000+ triple quadrupole mass spectrometer (AB SCIEX, Boston, USA). Multiple-reaction monitoring was conducted to monitor the analytes and internal standards. The mass conditions are as follows: ion spray voltage $(-4500 \mathrm{~V})$, ion source gas $1\left(\mathrm{~N}_{2}, 60\right.$ Arb), ion source gas $2\left(\mathrm{~N}_{2}, 65 \mathrm{Arb}\right)$, curtain gas $\left(\mathrm{N}_{2}, 30 \mathrm{Arb}\right)$, source gas temperature $\left(550^{\circ} \mathrm{C}\right)$, collision gas $\left(\mathrm{N}_{2}, 10 \mathrm{~Pa}\right)$. The selected mass transitions were $\mathrm{m} / \mathrm{z} 480.2 \rightarrow 418.1$ for $\mathrm{RSV}$ and $\mathrm{m} / \mathrm{z} 557.6 \rightarrow 397.1$ for atorvastatin, respectively.

\section{Pharmacokinetic Profile of RSV In Vivo}

Male Sprague-Dawley rats aged 6-8 weeks and weighing between 230 and $260 \mathrm{~g}$ were obtained from the Experimental Animal Center of Nanchang University. All of the rats were allowed to adapt the environment in the breeding room with ideal laboratory conditions (temperature of $23-25^{\circ} \mathrm{C}$, the relative humidity of 45-55\%, $12 \mathrm{~h}$ light/ $12 \mathrm{~h}$ darkness cycle) and were given free access to standard diet and water. The study was approved by the Ethical Committee of Jiangxi Medical College, and all experiments were carried out in accordance with the requirements of the Animal Care and Use Committee of Jiangxi Medical College. After experiments, the rats were euthanized by intraperitoneal injection of $3 \%$ sodium pentobarbital.

All rats were acclimatized for 5 days before the experiments. The experimental rats were randomly divided into two groups, 6 in each group: the RSV group (RSV $10 \mathrm{mg}$. $\mathrm{kg}^{-1}+0.2 \%$ CMC-Na) and the $\mathrm{RSV}+\mathrm{SCU}$ group (RSV $\left.10 \mathrm{mg} \cdot \mathrm{kg}^{-1}+\mathrm{SCU} 50 \mathrm{mg} \cdot \mathrm{kg}^{-1}\right)$. For the RSV, $0.9 \%$ sodium chloride was used to prepare a suspension of $1 \mathrm{mg} \cdot \mathrm{mL}^{-1}$; for the SCU, 0.2\% CMC-Na was used to prepare a suspension of $5 \mathrm{mg} \cdot \mathrm{mL}^{-1}$. The gavage volume of both groups was $10 \mathrm{~mL}$. $\mathrm{kg}^{-1}$. The concentrations used in the animals were converted from the clinical dose. The treatment was administered by gavage in the morning before feeding. For rats, SCU or $0.2 \%$ CMC-Na (vehicle) was administered immediately after the RSV administration. In each group, 6 rats were maintained throughout the study, and they were used for jugular vein blood sampling $(0.2 \mathrm{~mL})$ at 0 (before), $0.250 .5,1.0,1.5$, 2.0, 4.0, 6.0, 8.0, 12.0, 18.0, $24.0 \mathrm{~h}$ after treatment, so as to obtain the concentration-time profile data. A heparinized $0.9 \% \mathrm{NaCl}$ injectable solution was applied to compensate for blood loss after each blood sampling. The sampled blood was stored in a heparinized tube, and the plasma was separated by centrifugation, and then stored at $-80^{\circ} \mathrm{C}$ for further analysis. Plasma RSV concentrations were quantified using LC/MS/MS. $C_{\max }$ and $t_{\max }$ were obtained by analyzing the concentration-time data. The area under the RSV concentration-time curve from 0 to $24 \mathrm{~h}\left(\mathrm{AUC}_{0-24 \mathrm{~h}}\right)$ was calculated according to the linear trapezoidal rule. $k$ represents the elimination rate constant as determined from the terminal slope of the $\log$ concentration-time plot and the elimination half-life $\left(t_{1 / 2}\right)=0.693 / k$. The clearance as $\mathrm{CL}=$ Dose $/$ $\mathrm{AUC}_{0-\infty}$. The apparent systematic clearance $(\mathrm{CL} / \mathrm{F})$ was calculated as $\mathrm{CL} / \mathrm{F}=\mathrm{Dose} / \mathrm{AUC}_{0-\infty} /$ weight. The lower limit of quantification (LLOQ) of plasma was $1 \mathrm{ng} \cdot \mathrm{mL}^{-1}$, the dynamic 
range of plasma was $1-800 \mathrm{ng} \cdot \mathrm{mL}^{-1}$, and the intra- and interday coefficients of variation were less than $10 \%$.

\section{Statistical Analysis}

In vitro data from three independent experiments were analyzed using one-way ANOVA, followed by a Dunnett's post hoc test or by Student's t test. The $\mathrm{AUC}_{0-24 \mathrm{~h}}, t_{1 / 2}, C_{\max }, t_{\max }$, $\mathrm{CL}$ and $\mathrm{CL} / \mathrm{F}$ values of RSV after treatment with placebo and SCU were analyzed using paired Student's t test. Unless otherwise stated, the results are expressed as mean \pm standard deviation (SD) in the text, tables, and figures. All data were analyzed using SPSS software (version 19.0, Chicago, IL). $P<0.05$ was considered as statistically significant.

\section{RESULTS}

\section{Transporter Expression in HEK293T by Western Blotting}

The results showed that the blank HEK293T and HEK293TMOCK cells contained barely any target proteins, while the western blotting of hOATP1B3 and rOATP1B2 transfected cell lines exhibited a distinctive band, indicating that

Fig. I The protein expression of hOATPIB3 and rOATPIB2 in cells. The immunoblots shown in $\mathbf{a} \& \mathbf{c}$. Results of integrated optical density analysis is shown in $\mathbf{b} \& \mathbf{d}$. (mean $\pm \mathrm{SD}, n=3) \cdot \mathrm{Na}^{+} / \mathrm{K}^{+}$-ATPase is a membrane protein. **indicates a significant difference compared with the HEK293T-MOCK group $(P<0.0 \mathrm{I})$. (a)

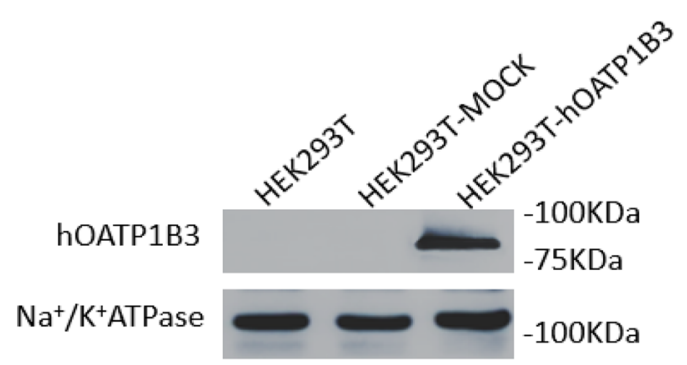

(c)

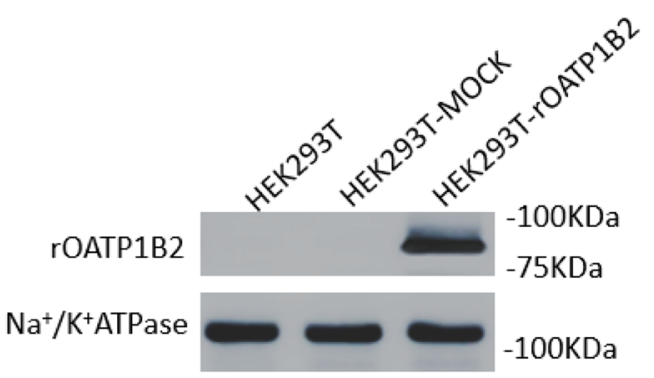

HEK293T cells successfully expressed the target gene after transfection, as shown in Fig. 1.

\section{In Vitro Impact of SCU on the hOATP I B3- and rOATP I B2-Mediated Uptake of RSV}

The RSV uptake and inhibition experiment confirmed that RSV was transported by hOATP1B3 and rOATP1B2, and the uptakes in HEK293T-hOATP1B3 and HEK293TrOATP1B2 cells were substantially higher than in HEK293T-MOCK cells (4.9-fold and 5.7-fold). RIF $(50 \mu \mathrm{M})$ inhibited RSV uptake in HEK293T-hOATP1B3. GA $(20 \mu \mathrm{M})$ inhibited RSV uptake in HEK293TrOATP1B2 cells, and SCU $(50 \mu \mathrm{M})$ inhibited RSV uptake in HEK293T-hOATP1B3 and HEK293T- rOATP1B2. SCU exerted a notable inhibitory effect on the hOATP1B3and rOATP1B2-mediated uptake of RSV in a concentrationdependent manner, and the half-maximal inhibitory concentration (IC50) values were $45.54 \pm 6.67 \mu \mathrm{M}(95 \%$ CI: 38.04, $53.04)$ and $27.58 \pm 3.97 \mu \mathrm{M}(95 \%$ CI: 23.08, 32.08), respectively, as shown in Fig. 2.

\section{In Vivo Impact of SCU on the Pharmacokinetics of RSV}

Table I lists the main pharmacokinetic parameters of RSV. Figure 3 indicates the average plasma concentration profile of 
(a)

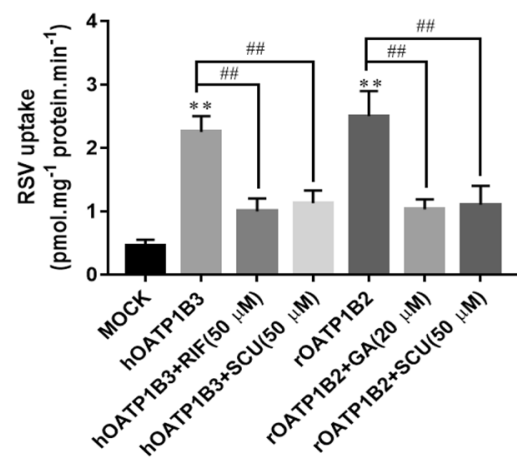

(b)

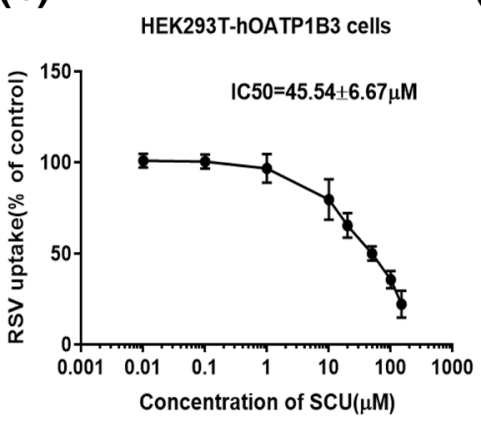

(c)

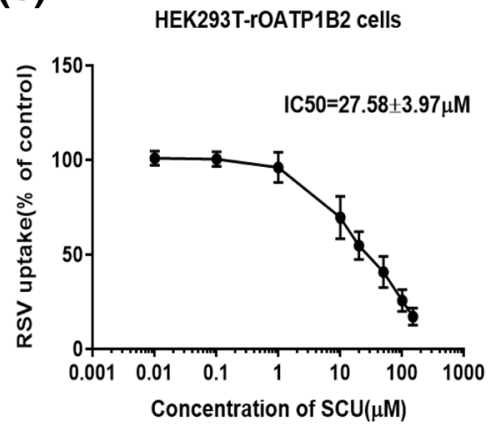

Fig. 2 Inhibition of hOATP IB3- and rOATP I B2-mediated RSV transport. SCU (50 $\mu$ M), RIF (20 $\mu$ M), and GA (50 $\mu$ M) inhibition on hOATP I B3 and rOatp I b2mediated RSV in cells (a). SCU inhibited the hOATPIB3- (b) and rOATPIB2-(c) mediated RSV uptake (50 $\mu$ M) in a concentration-dependent manner (the data are denoted as a percentage of control (RSV alone)). All data is indicated by mean \pm SD $(n=3)$. **indicates a significant statistical difference from HEK293TMOCK cells $(P<0.0 \mathrm{I})$, \#\# indicates a significant statistical difference from the RSV alone $(P<0.0 \mathrm{I})$.

RSV when combined with the $0.2 \%$ GMC-Na or SCU. Treatment of SCU led to a significant increase in the $C_{\max }$ of $\mathrm{RSV}$ by $27.4 \%(P=0.04)$ and $\mathrm{AUC}_{0-24}$ by $37.7 \%(P=$ 0.006), respectively. Subsequent to SCU treatment, the CL and CL/F of RSV was reduced significantly by $29.2 \%(P=$ $0.007)$ and $28.1 \%(P=0.008)$ compared with the RSV groups, respectively. And there was no significant impact on the observed $t_{1 / 2}$ and $t_{\max }$ of RSV.

\section{DISCUSSION}

In this study, we focused on the interactions of SCU with human hepatocellular uptake transporter hOATP1B3 and rOATP1B2. First, a single transporter cDNA was successfully transfected into the HEK293T cell line (Fig. 1). Then, we observed that HEK293T-hOATP1B3 and HEK293TrOATP1B2 cells had higher uptake (approximately 4.9-fold and 5.7-fold) compared with HEK293T-MOCK cells. RIF

Table I Pharmacokinetic parameters of RSV

\begin{tabular}{llll}
\hline Parameters & RSV group & RSV + SCU group & $P$ value \\
\hline Half life $\left(t_{1 / 2}, h\right)$ & $4.96 \pm 1.77$ & $5.07 \pm 1.95$ & 0.593 \\
$t_{\max }(h)$ & $1.46 \pm 0.15$ & $1.51 \pm 0.18$ & 0.547 \\
$C_{\max }\left(\mathrm{ng} \cdot \mathrm{mL}^{-1}\right)$ & $387.67 \pm 70.79$ & $494.01 \pm 84.53 * *$ & 0.040 \\
$\mathrm{CL}\left(\mathrm{L} \cdot \mathrm{h}^{-1}\right)$ & $10.68 \pm 1.88$ & $7.50 \pm 1.12^{*} * *$ & 0.009 \\
$\mathrm{CL} / \mathrm{F}\left(\mathrm{L} \cdot \mathrm{h}^{-1} \cdot \mathrm{kg}^{-1}\right)$ & $2.67 \pm 0.47$ & $1.92 \pm 0.28 * * *$ & 0.008 \\
$\mathrm{AUC} \mathrm{C}_{0-24 \mathrm{~h}}\left(\mathrm{ng} \cdot \mathrm{mL}^{-1} \cdot \mathrm{h}\right)$ & $3841 \pm 675$ & $5287 \pm 766 * *$ & 0.006 \\
\hline
\end{tabular}

The data is expressed as mean $\pm S D,(n=6) . t_{\max }$ (time to reach $C_{\text {max }}$ ) data is expressed as medians with range. $\mathrm{AUC}_{0-24} \mathrm{~h}$, area under the plasma drug concentration-time curve from 0 to $24 \mathrm{~h} ; C_{\max }$, peak plasma drug concentration; $t_{1 / 2}$, elimination half-life; $C L$, clearance; $C L / F$, apparent clearance. **indicates a significant statistical difference from the RSV group $(P<0.0$ I $)$
$(50 \mu \mathrm{M})$ and $\mathrm{GA}(20 \mu \mathrm{M})$ significantly reduced the higher uptake of RSV in transporter transfection cells. SCU significantly inhibited the hOATP1B3-, and rOATP1B2-mediated RSV uptake in vitro in a concentration-dependent manner, with IC50 values of $45.54 \pm 6.67 \mu \mathrm{M}$ and $27.58 \pm 3.97 \mu \mathrm{M}$, respectively (Fig. 2). HEK293T cells are one of the commonly used in vitro models to study the correlation between drug transporters and substrates (21). In these HEK293T cells, the transfection rate was determined to be greater than $80 \%$, which could meet our design requirements. In addition, according to Dong's research method, the results of the cytotoxicity test showed that $\mathrm{SCU}(50 \mu \mathrm{M}), \mathrm{RSV}(50 \mu \mathrm{M})$, and GA $(20 \mu \mathrm{M})$ posed no significant toxicity to cells, consistent with studies by Dong (21) and Liu (13). As a widely used active ingredient in Chinese medicine, we are also concerned about the concentration of SCU in vivo. Haisheng You et al. (22) found that the $C_{\max }$ and $\mathrm{AUC}_{0-\infty}$ of $\mathrm{SCU}\left(80 \mathrm{mg} \cdot \mathrm{kg}^{-1}\right)$ by oral gavage were $288.0 \pm 75.2 \mu \mathrm{g} \cdot \mathrm{L}^{-1}$ and $5.9 \pm 1.7 \mu \mathrm{g} \cdot \mathrm{mL}^{-}$ ${ }^{1} \cdot \mathrm{h}$ in rats. Zhong et al. (23) found that after a single p.o. administration of $60 \mathrm{mg}$ of scutellarin to 20 healthy subjects, the $C_{\max }$ of scutellarin were low $\left(87.0 \pm 29.1 \mathrm{ng} \cdot \mathrm{mL}^{-1}\right)$. In this study, we found that SCU can influence the pharmacokinetics of RSV, despite low plasma concentrations in viwo. After cofeeding SCU, the $\mathrm{AUC}_{0-24 \mathrm{~h}}$ and $C_{\max }$ of RSV in rats increased to $27.4 \%(P=0.04)$ and $37.7 \%(P=0.006)$, respectively. Moreover, SCU reduced the CL and CL/F of RSV by $29.2 \%(P=0.009)$ and $28.1 \%(P=0.008)$, indicating that SCU can have a considerable impact on the pharmacokinetic characteristics of RSV in rats (Fig. 3). In addition, Our previous intestinal absorption studies have shown that SCU does not affect the absorption rate constant or absorption coefficient of RSV (20). Therefore, this pharmacokinetic effect may not be attributed to the effect of SCU on the intestinal tract, instead, this inhibition on uptake may occur in the liver and the inhibitory effect of SCU on RSV may be mediated by liver OATP. 
Fig. 3 Average plasma concentration-time profiles of RSV following an oral administration of RSV $\left(10 \mathrm{mg} \cdot \mathrm{kg}^{-1}\right)$ to rats in the presence and absence of SCU $\left(50 \mathrm{mg} \cdot \mathrm{kg}^{-1}\right)(\mathbf{a})$ and individual values for $\mathrm{AUC}_{0-24 \mathrm{~h}}(\mathbf{b})$ (mean \pm $\mathrm{SD}, n=6$ ). **indicates a significant statistical difference from RSV group $(P<0.0 \mathrm{l})$. (a)

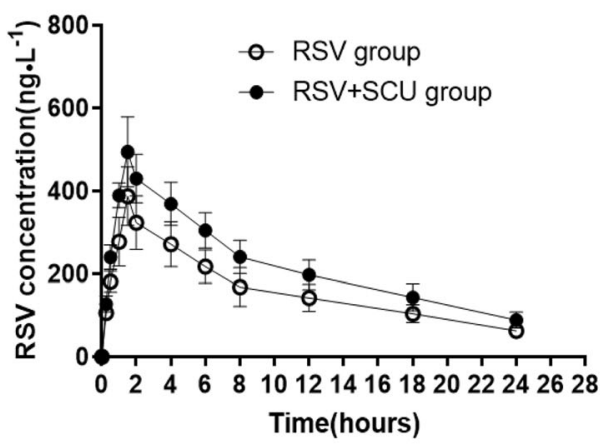

(b)

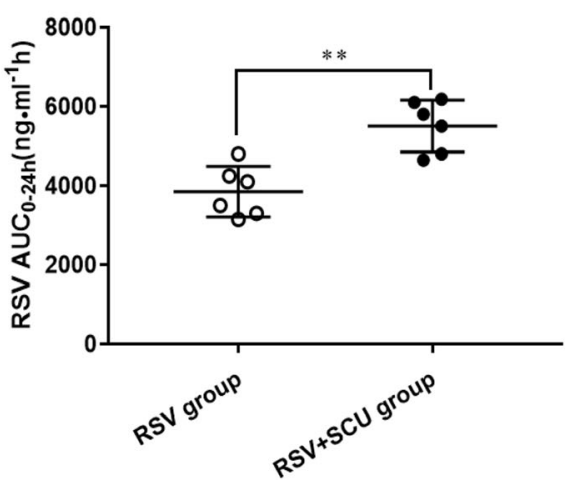

OATP transporters are classified into a large family of membrane proteins that mediate the sodium-independent cellular uptake of various amphipathic compounds, including hormones, bile acids, eicosanoids, environmental toxins, and many clinical drugs (24). Therefore, many drug interactions are mediated by OATP. In humans, both hOATP1B1 and hOATP1B3 genes are located on the short arm of chromosome 12 (gene locus $12 \mathrm{p} 12$ ), and they have up to $80 \%$ sequence homology. Both transporters have been described to be highly expressed in the human liver (25). OATP1B2 in the rodent is similar to hOATP1B1 and hOATP1B3, and these three transporters are uniquely expressed in the liver (26). OATP1B2 is most important for transporting unconjugated bile acids into the livers of mice (27). In addition, DeGorter et al. (28) found that OATP1B2 in mice is critical for the hepatic uptake of atorvastatin and rosuvastatin but not simvastatin acid. Mice OATP1B2 also plays an important role in the disposition of pravastatin and lovastatin (29). Higgins et al. (30) studied the pharmacokinetics of three statins (pravastatin, atorvastatin, and simvastatin) using OATP1B2-null mice, and also humanized OATP1B1 and OATP1B3 in mice. Therefore, OATP1B2 in rodents and hOATP1B1/1B3 are often studied in comparison.

According to a recent study, the targeted disruption of murine OATP1B2 may cause significant alteration to the disposition of prototypical drug substrates pravastatin and rifampin, and OATP1B2 has a high consistency with hOATP1B1 and hOATP1B3 in uptake function (18). In the present study, we propose that the changes in RSV pharmacokinetics are mainly attributed to the SCU mediated inhibition of OATP1B2 in rats. Due to the high degree of homology between human OATP1B1/1B3 and rOATP1B2, we believe that the studies on rats can provide a reference for studies on humans (31). However, the changes in OATPs expression between human and rat primary hepatocytes are not completely parallel, and there is no strict one-to-one mapping between human OATPs genes and rodent OATPs genes (32). In addition, it has been shown that single nucleotide polymorphisms of human OATP1B1/1B3 can affect the function of transporters, which may cause changes in the pharmacokinetics, efficacy, and side effects of certain drugs (33). Further human studies are needed to confirm our conclusions.

In summary, our study demonstrated for the first time that SCU has an inhibitory effect on hOATP1B3-mediated transport of RSV in vitro. These results suggest that $\mathrm{SCU}$ is the perpetrator of hepatic hOATP1B3 mediated DDI. Besides, it is speculated that SCU has a moderate inhibitory effect on the pharmacokinetics of RSV in humans mediated by hOATP1B3. This study is expected to show the clinical significance for patients taking SCU and hOATP1B3 substrate drugs simultaneously.

Acknowledgements and Disclosures. This work was supported by China National Science Foundation for Distinguished Young Scholars (Grant No: 81202583); Jiangxi Education Department Science Plan (Key Project, Grant No: GJJ151335). The authors declare no competing interests.

\section{AUTHOR'S CONTRIBUTIONS}

Jianming Liu, Yongmei Guo, and Huiting Zhu participated in the study design. Jianming Liu, Yongmei Guo, and Yanqi Xu conducted the experiments and performed data analysis. Jianming Liu and Huiting Zhu. Wrote and revised the manuscript, and supervised the study.

Data Availability The raw data supporting the conclusions of this manuscript will be made available by the authors, without undue reservation, to any qualified researcher.

Open Access This article is licensed under a Creative Commons Attribution 4.0 International License, which permits use, sharing, adaptation, distribution and reproduction in any medium or format, as long as you give appropriate credit to the original author(s) and the source, provide a link to the Creative Commons licence, and indicate if changes were made. The images or other third party material in this article are included in the article's Creative Commons licence, unless indicated otherwise in a credit line to the material. If material is not included in the article's Creative Commons licence and 
your intended use is not permitted by statutory regulation or exceeds the permitted use, you will need to obtain permission directly from the copyright holder. To view a copy of this licence, visit http://creativecommons.org/licenses/by/4.0/.

\section{REFERENCES}

1. Yu WJ, Ma MY, Chen XM, Min JY, Li LR, Zheng YF, et al. Traditional Chinese medicine and constitutional medicine in China, Japan and Korea: a comparative study. Am J Chinese Med. 2017;45:1-12.

2. Li PW, Qiang M. Clinical benefits and pharmacology of scutellarin: a comprehensive review. Pharmacol Ther. 2018;190:105-27.

3. Gao J, Chen G, He H, Liu C, Xiong X, Li J, et al. Therapeutic effects of Breviscapine in cardiovascular diseases: a review. Front Pharmacol. 2017;8:289.

4. Yang W, Li L, Xie YM, Zhuang Y, Yang W. Treatment outcomes of parenterally administered dengzhan xixin for treatment of cerebral infaction based on real world hospital injection system data. Zhongguo Zhong Yao Za Zhi. 2013;38:3141-9.

5. Liu JM, Yang YX, Ye Y. Effect of scutellarin on the plasma concentration and tissue distributions of rosuvastatin in rats. Chin J Clin Pharmacol. 2018;34:576-9.

6. Lin SS, Tsai CL, Tu CY, Hsieh CL. Reducing drug-herb interaction risk with a computerized reminder system. Ther Clin Risk Manag. 2015;1 1:247-53.

7. Han BY, Yao YH. Pharmacokinetic interaction and the mechanisms of combination of Chinese and western medicines. Medical Recapitulate. 2014;20:2996-8.

8. Mitchell RM, Hartmut J. Metabolism and disposition of acetaminophen: recent advances in relation to hepatotoxicity and diagnosis. Pharm Res. 2013;30(9):2174-87.

9. Tornio A, Niemi M, Neuvonen PJ, Backman JT. Drug interactions with oral antidiabetic agents: pharmacokinetic mechanisms and clinical implications. Trends Pharmacol. 2012;33:312-22.

10. König J, Muller F, Fromm MF. Transporters and drug-drug interactions: important determinants of drug disposition and effects. Pharmacol Rev. 2013;65:944-66.

11. Gao C, Zhang H, Guo Z, You T, Chen X, Zhong D. Mechanistic studies on the absorption and disposition of scutellarin in humans: selective OATP2B1-mediated hepatic uptake is a likely key determinant for its unique pharmacokinetic characteristics. Drug Metab Dispos. 2012;40:2009-20.

12. Alam K, Crowe A, Wang XY, Zhang PY, Ding K, Li L, et al. Regulation of organic anion transporting polypeptides (OATP) 1B1- and OATP1B3-mediated transport: an updated review in the context of OATP-mediated drug-drug interactions. Int J Mol Sci. 2018;19:855.

13. Liu JM, Guo Y, Liu KQ Ye XY, Wang F, Xu Y, et al. Scutellarin inhibition of the rosuvastatin uptake in rat hepatocytes and the competition for organic anion transporting polypeptide 1B1 in HEK293T cells. Sci Rep. 2020;10:1308-16.

14. König J, Cui Y, Nies AT, Keppler D. Localization and genomic organization of a new hepatocellular organic anion transporting polypeptide. J Biol Chem. 2000;275:23161-8.

15. Vavricka SR, Van MJ, Ha HR, Meier PJ, Fattinger K. Interactions of rifamycin $\mathrm{SV}$ and rifampicin with organic anion uptake systems of human liver. Hepatology. 2002;36:164-72.

16. Kitamura S, Maeda K, Wang Y, Sugiyama Y. Involvement of multiple transporters in the hepatobiliary transport of rosuvastatin. Drug Metab Dispos. 2008;36:2014-23.

17. Cattori V, Hagenbuch B, Hagenbuch N, Stieger B, Ha R, Winterhalter KE, et al. Identification of organic anion transporting polypeptide 4 (Oatp4) as a major full-length isoform of the liverspecific transporter-1 (rlst-1) in rat liver. FEBS Lett. 2000;474:242-5.

18. Hani Z, Henriette E, Rommel G, Tirona, Melissa LG, Leslie AO, et al. Targeted disruption of murine organic anion-transporting polypeptide 1b2 (oatp1b2/Slcolb2) significantly alters disposition of prototypical drug substrates pravastatin and rifampin. Mol Pharm. 2008;74:320-9.

19. Liu XN, Cheng J, Zhang GG, Ding WT, Duan LG, Yang J. Engineering yeast for the production of breviscapine by genomic analysis and synthetic biology approaches. Nat Commun. 2018;9:448-56.

20. Liu JM, Guo YM, Yang YX, Wang J, Wang F. Influence of scutellarin on intestinal absorption of rosuvastatin in rats. Asiapacific tradional medicine. 2017;21:4-8.

21. DongJJ, Olaleye OE, Jiang RR, LiJ, Lu C, Du FF, Xu F, YangJL, Wang FQ Jia WW, Li C. Glycyrrhizin has a high likelihood to be a victim of drug-drug interactions mediated by hepatic organic anion-transporting polypeptide 1B1/1B3. Br J Pharmacol. 2018; 175:3486-503.

22. You HS, Dong YL, Xing JF, Zhang CL, Wang MY. Pharmacokinetic and tissue distribution study of scutellarin in rats. China Journal of Chinese Materia Medica. 2007;32:1688-92.

23. Chen XY, Gui L, Duan XT, Ma B, Zhong DF. Pharmacokinetics and metabolism of the flavonoid scutellarin in humans after a single oral administration. Drug Metab Dispos. 2006;34:1345-52.

24. Stefan O. Organic anion transporting polypeptide (OATP) transporter expression, localization and function in the human intestine. Pharmacol Ther. 2019;195:39-53.

25. Ho RH, Tirona RG, Leake BF, Glaeser H, Lee W, Lemke CJ, Wang Y, Kim RB. Drug and bile acid transporters in rosuvastatin hepatic uptake: function, expression, and pharmacogenetics. Gastroenterology. 2006;130(6):1793-806.

26. Pan Q Zhang X, Zhang L, Cheng Y, Zhao N. Solute carrier organic anion transporter family member $3 \mathrm{Al}$ is a bile acid efflux transporter in cholestasis. Gastroenterology. 2018;155:1578-92.

27. Csanaky IL, Lu H, Zhang Y, Ogura K, Choudhuri S, Klaassen CD. Organicanion-transporting polypeptide $1 \mathrm{~b} 2$ (Oatplb2) is important for the hepatic uptake of unconjugated bile acids: studies in Oatplb2-null mice. Hepatology. 2011;53:272-81.

28. DeGorter MK, Urquhart BL, Gradhand U, Tirona RG, Kim RB. Disposition of atorvastatin, rosuvastatin, and simvastatin in oatplb2 $-/-$ mice and intraindividual variability in human subjects. J Clin Pharmacol. 2012b;52:1689-97.

29. Zaher H, Schwabedissen HE, Tirona RG, Cox ML, Obert LA. Targeted disruption of murine organic anion-transporting polypeptide 1 b2 (Oatp1b2/Slcolb2) significantly alters disposition of prototypical drug substrates pravastatin and rifampin. Mol Pharmacol. 2008;74:320-9.

30. Higgins JW, Bao JQ Ke AB, Manro JR, Fallon JK. Utility of Oatpla/1b-knockout and OATP1B1/3-humanized mice in the study of OATP-mediated pharmacokinetics and tissue distribution: case studies with pravastatin, atorvastatin,simvastatin, and carboxydichlorofluorescein. Drug Metab Dispos. 2014;42:182-92.

31. Hagenbuch B, Meier PJ. The superfamily of organic anion transporting polypeptides. Biochim Biophys Acta. 2003;1609:1-18.

32. Hagenbuch B, Meier PJ. Organic anion transporting polypeptides of the OATP/SLC21 family: phylogenetic classification as OATP/ SLCO superfamily, new nomenclature and molecular/functional properties. Pflug Arch. 2004;447:653-65.

33. Gong IY, Kim RB. Impact of genetic variation in OATP transporters to drug disposition and response. Drug Metab Pharmacokinet. 2013;28:4-18.

Publisher's Note Springer Nature remains neutral with regard to jurisdictional claims in published maps and institutional affiliations.? 